\title{
Bacterial Colonization and Dental Implants: A Microbiological Study
}

\author{
Jasmani Bin Ab Manaf ${ }^{1}$, Shaifulizan Ab Rahman ${ }^{1}$ (D), Sanjida Haque ${ }^{(\mathbb{D}}$, Mohammad Khursheed \\ $\mathrm{Alam}^{3}$ (D)
}

${ }^{1}$ Oral and Maxillofacial Surgery Department, School of Dental Sciences, Universiti Sains Malaysia, Kelantan, Malaysia. ${ }^{2}$ Orthodontic Unit, School of Dental Sciences, Universiti Sains Malaysia, Kelantan, Malaysia.

${ }^{3}$ Orthodontic Department, College of Dentistry, Jouf University, Sakaka, Kingdom of Saudi Arabia.

Author to whom correspondence should be addressed: Professor Dr. Shaifulizan Ab Rahman, Oral and Maxillofacial Surgery Department, School of Dental Science, Universiti Sains Malaysia, Kubang Kerian, Kota Bharu, Kelantan, Malaysia. Phone: +609-7675821. E-mail: shaiful@usm.my.

Academic Editors: Alessandro Leite Cavalcanti and Wilton Wilney Nascimento Padilha

Received: 23 October 2019 / Accepted: 18 May 2020 / Published: 09 June 2020

How to cite this article: Manaf JBA, Rahman SA, Haque S, Alam MK. Bacterial colonization and dental implants: a microbiological study. Pesqui Bras Odontopediatria Clín Integr. 2020; 20:e4979. https://doi.org/10.1590/pboci.2020.105

\begin{abstract}
Objective: To compare colony forming unit (CFU) of oral bacterial from buccal mucosa and lingual buccal tongue among patients with a dental implant and normal oral hygiene individuals without a dental implant. Material and Methods: Twenty-six individuals with a dental implant and twenty-six individuals without dental implants were included in this study. The samples were sent to the laboratory to culture with Brain Heart Infusion Broth (BHI), prepared serial dilution and then spread to the blood agar. CFU was counted when a single layer of bacteria is formed on the blood agar at any dilution level. An independent- $T$ test was used to compare the means different of CFU oral bacterial between control and test groups from buccal mucosa and lingual buccal mucosa, respectively. Results: Buccal mucosa control group (186.19 \pm 5.61$)$ and test group $(186.65 \pm 6.24)(\mathrm{p}>0.05)$. The result from the lingual buccal tongue control group (198.38 \pm $6.12)$ and test group $(197.96 \pm 6.50)(\mathrm{p}>0.05)$. There was no significant difference between the control group and test group CFU bacterial load. Conclusion: The presence of implants in the oral cavity do not interfere or worsen the oral condition; nevertheless, the effect of implants surrounding oral flora is similar to natural teeth.
\end{abstract}

Keywords: Dental Materials; Dental Implantation, Endosseous; Peri-Implantitis; Microbiology. 


\section{Introduction}

The implant is known as one of the most acceptable dental treatment today. Dental implants have become increasingly popular for the management of tooth loss [1]. Titanium dental implants have been used in oral rehabilitation for replacing one or more missing teeth [2]. Dental implants are for the rehabilitation of edentulous patients and improve function and esthetics [3]. Along with the popularity of dental implants as dental rehabilitation for missing teeth or teeth, there are many studies done that are associated to the osseointegration, which mainly represent imaging and RFA (resonance frequency analysis) because of the interest in bony stability [4].

Failing implants because of loss of supporting bone and soft tissue where the evidence of mobility occurred [5]. The implant failed when infection at the gingival margin appears analogous to gingivitis implants may have a probable pocket around the implant teeth [6]. However, the information or research on peri-implant soft tissue related conditions should not be neglected, particularly related to the microorganism. Peri-implantitis was defined as an inflammatory condition involving dental implants, surrounding mucosa and bone, which lose supporting bone [7]. The cause of dental implant failure has been associated with surgical procedures, anatomic considerations, and bacterial contamination of the implant [8]. Implant failures due to peri-implantitis because the existence of diseases on implant surfaces have a significant role in potentially affected osseointegration of the implant into the surrounding bone [9].

A successful implant treatment depends on the lack of inflammation in peri-implant tissue and the oral cavity where the implant's surface could get colonized by microorganisms [10]. The oral cavity is residences by various microorganisms or bacteria called normal oral flora; these bacteria are responsible for dental diseases such as caries and periodontal or gum disease. About 400 different microbial species are capable of colonizing the dentate estimated in the oral cavity and that any individual may harbor over 150 different species [5]. The mouth provides an environment for the growth of the microorganisms as compared to any other part of the human body [11].

The pattern of microorganisms that colonized the oral cavity also varies among the different hosts depending on the oral hygiene status, which in normal healthy oral cavity mainly residence by gram-positive aerobic whereas the gram-negative and anaerobic are found in poor oral hygiene person. The oral cavity is the diverse microbial community found on the tooth surface and salivary origin [12]. The peri-implant infection comes from the study on a plaque from the patient's mouth [11]. Therefore, the knowledge on the pattern of microorganism colonized oral cavity of dental implant patient is important in warranting the longevity of implant treatment by providing the dentist with an evidence-based finding which is beneficial in post-implant treatment maintenance.

In the implant surface, the initial adhesion and the colonization of bacteria are considered to play a key role in the pathogenesis of infections related to biomaterials [13]. In natural teeth or healthy oral cavity, bacterial is prevented to attach to periodontal tissue where they are limited physically by the gingival mucosa, which forms a seal around the neck of the tooth [14]. The other natural protective measures that prevent the invasion of the microorganism into periodontal tissue, are intact, attached gingiva and crevicular fluid, known as biological width. In the oral cavity, there are bacteria on the tongue, buccal mucosa, tooth-adherent, coronal and apical to the gingival margin and saliva [15].

Implant longevity depends on multiple factors, including oral cavity health status, which is closely related to a load of bacteria colonized, which might harm the oral tissue and implant. Therefore, knowing the load of bacteria colonized oral cavity in dental implant patients can improve and optimize the maintenance care 
and warrant the survival and longevity of the dental implant. This study aimed to determine and compare the CFU of oral bacteria in a dental swab from implant patients and normal patients as the control group.

\section{Material and Methods}

Selection of Subjects and Sampling

A total of 52 patients (26 implant patients and 26 control group) were included in this study. Patients who received dental treatment at Klinik Pergigian Pakar Hospital, Universiti Sains Malaysia, were selected as the test group for the oral swab. Healthy patients' (patients' do not have the implant in the oral cavity with good hygiene) sample also collected as controls for this study. The sampling procedure took 1-3 minutes.

Program PS: Power and Sample Size Calculation Software was used to calculate the sample size based on comparing two means. To detect the difference of 2 (x 104) CFU with $95 \%$ power and alpha 0.05 , we need 26 subjects in each group. Standard Deviation was set as 2.5 (x104) CFU [16]: n = z x $\sigma / \Delta$. A total of 52 subjects were selected (26 subjects with a dental implant and 26 subjects without the dental implant).

\section{Collection of Patient Sample}

Swab sample from patients and control was collected with sterile cotton swab sticks. The swab samples from both groups were placed into Stuart transport medium and later transferred to the microbiology laboratory. Oral swabs were taken from the lateral border of the tongue and buccal mucosa of the patient's mouth [17].

\section{Bacterial Culture}

Brain Heart Infusion Broth (BHI Broth)

BHI is the most commonly used medium to culture this type of bacteria. To prepare $500 \mathrm{~mL}$ of BHI broth, $15 \mathrm{gm}$ of the BHI broth powder was added to $500 \mathrm{~mL}$ distilled water. The mixture then mixed thoroughly. The BHI broth solution then was aliquot $500 \mathrm{uL}$ into the universal bottle. This bottle was labeled and marked with autoclave tape before being autoclaved (Figure 1a).

\section{Mueller-Hilton Agar Preparation}

Five percent sheep blood and nicotinamide adenine dinucleotide be added when susceptibility testing is done on Streptococcus species. It is a non-selective, non-differential medium; that means almost all organisms plated on here was grow as well as it contains starch that absorbs toxins released from bacteria. Thirty-eight gram of the powder in $1 \mathrm{~L}$ of purified water was suspended. Mix thoroughly and heat with frequent agitation and boil for 1 minute to completely dissolve the powder. Autoclaved at $121^{\circ} \mathrm{C}$ for 15 minutes and cooled the medium to $45-50^{\circ} \mathrm{C}$ and aseptically add $5 \%$ sterile defibrinated sheep blood. Pour cooled Mueller Hinton agar into sterile Petri dishes on a level, horizontal surface to give a uniform depth of about 4 $\mathrm{mm}$ (60-70 mL of medium for $150 \mathrm{~mm}$ plates and $25-30 \mathrm{~mL}$ for $100 \mathrm{~mm}$ plates) and cool to room temperature (Figure 1b). The prepared medium was checked to ensure the final $\mathrm{pH}$ is $7.3 \pm 0.1$ at $25^{\circ} \mathrm{C}$.

\section{Inoculation of Bacterial}

The sample from the buccal mucosa and lateral border of the tongue was taken by gently pressing a sterile cotton swab stick onto the palate surface. The sample was placed into the sterile bottle with BHI Broth, was incubate 24 hours in an incubator with fixed temperature $\left(37^{\circ} \mathrm{C}\right)$. The two normal media was used in 
bacteriology are a clear soup-like liquid nutrient broth, usually in tubes, and nutrient agar, which is set into jelly by the addition of a seaweed extract called agar, and when melted poured into glass or plastic petri dishes - also known as plates. Bacterial was introduced to the media (inoculated) by spread technique. Usually, the bacteria e.g., from a drop-in, a glass spreader, will be spread on the surface of (ready set) agar. A similar technique is used with broth cultures (Figure 1c).

\section{McFarland Test}

Standards were used as turbidity standards in the preparation of suspensions of microorganisms. The McFarland 0.5 standards have particular application in the preparation of bacterial inoculate for performing antimicrobial susceptibility testing (Figure 1d).

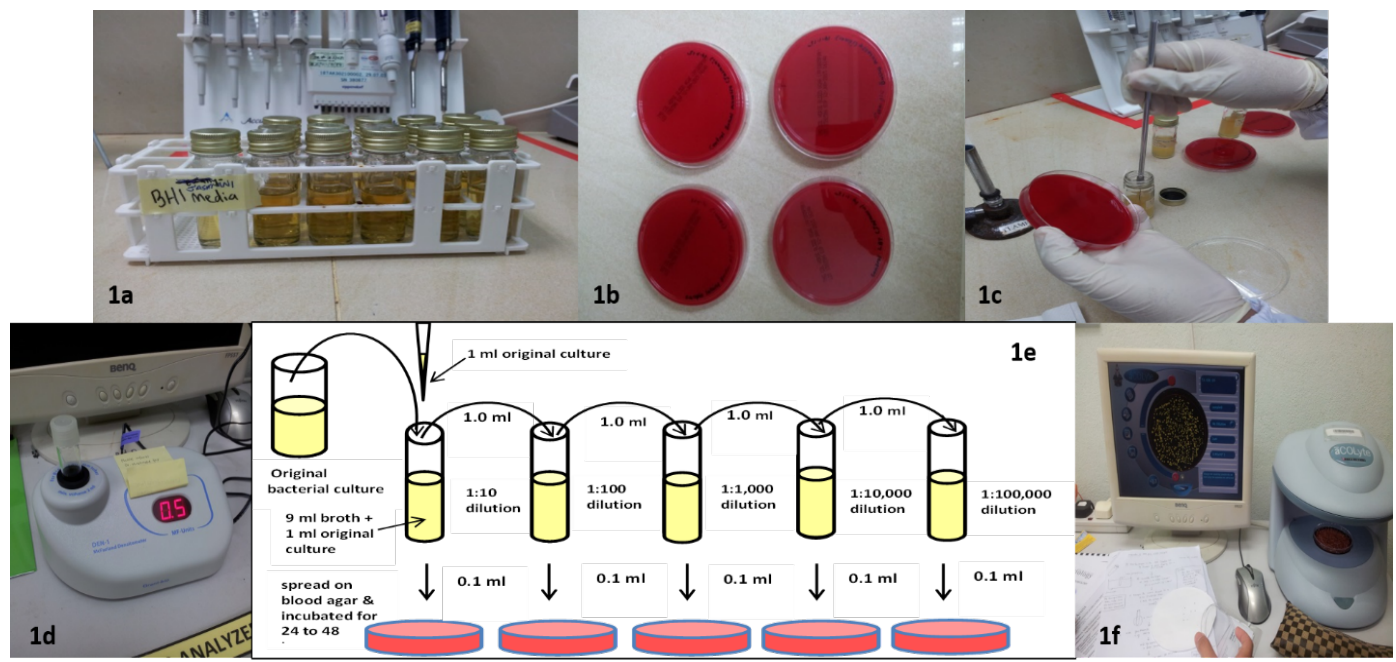

Figure 1a. BHI Broth preparation in the universal bottle; 1b. Blood agar preparation in sterile petri dishes; 1c. Inoculation of bacteria on the blood agar using spread technic; 1d. McFarland test for quality control; 1e. Serial dilution diagram; 1f. Bacterial counted used Acolyte Machine.

\section{Bacterial Dilution}

Bacteria commonly grow up to densities, although the maximum densities vary tremendously depending on the species of bacteria and the media they are growing in. Therefore, to get readily countable numbers of bacteria to make a wide range of dilutions and assay all of them to have one or two dilutions with countable numbers. Ten-fold serial dilutions (Figure 1e) of the bacteria that cover the whole, probably the range of concentrations. We then transferred $0.1 \mathrm{~mL}$ of each dilution to an agar plate of blood agar and we are only spread 0.1 mL. The samples were cultured on blood agar in duplicates. Cultured was incubated for 24 to 48 hours.

\section{Colony Forming Unit (CFU) Counting}

Only plates (or replicate plates from the same dilution) with 30-300 colonies were counted (Figure 1f).

Statistical Analysis

The data collected were analyzed using IBM SPSS Statistics software, version 22. All values were expressed as mean \pm standard error of the mean (SEM) in each graph and in the average and standard deviation (SD) in the table. The normal distribution of the data was determined by the Shapiro-Wilk normality 
test to assure that the data is normally distributed $(\mathrm{p}>0.05)$. Levene test results were seen for determining homogeneity or uniformity of variance (homogeneous for $\mathrm{p}>0.05$ ). The data collected were normally distributed and an independent-T test was used to compare the means different of CFU oral bacterial between control and test groups from buccal mucosa and lingual buccal mucosa, respectively.

Ethical Aspects

This study was approved by the Ethical Committee of the Hospital Universiti Sains Malaysia (USM/JEPeM/14110459), which complies with the Declaration of Helsinki.

\section{Results}

$\mathrm{CFU}$ of oral bacteria was measured from buccal mucosa part of both patients with the implant group and control group. There was no significant difference between the control group $(186.19 \pm 5.61)$ and the test group $(186.65 \pm 6.24 ; \mathrm{p}>0.05)$ (Figure 2$)$.

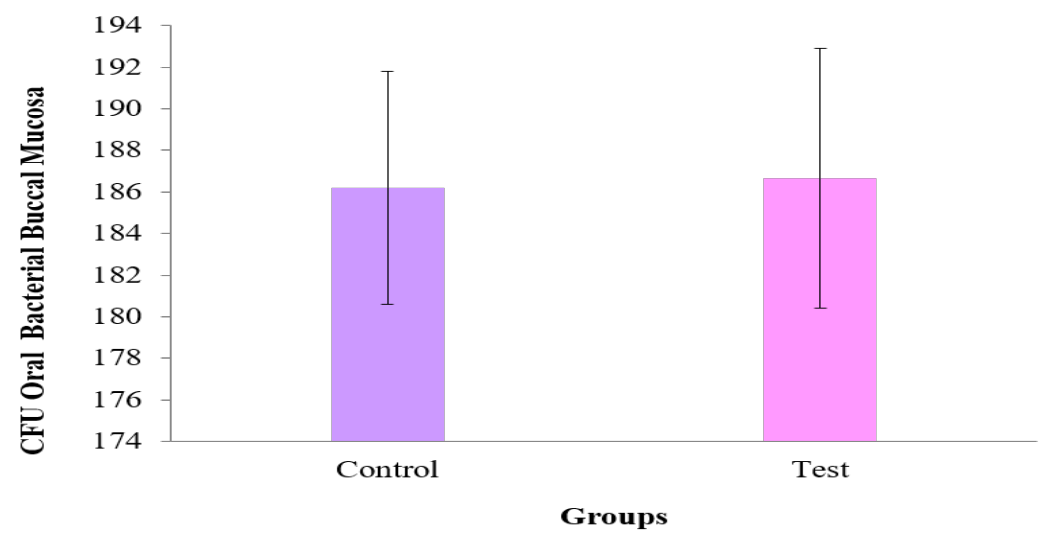

Figure 2. CFU oral bacterial buccal mucosa for the control group (without implant) and test group (with implant).

CFU of oral bacterial was measured from lingual buccal tongue part of both patients with implant group and control group. There was no significant difference between the control group $(198.38 \pm 6.12)$ and the test group (197.96 $\pm 6.50 ; \mathrm{p}>0.05)$ (Figure 3).

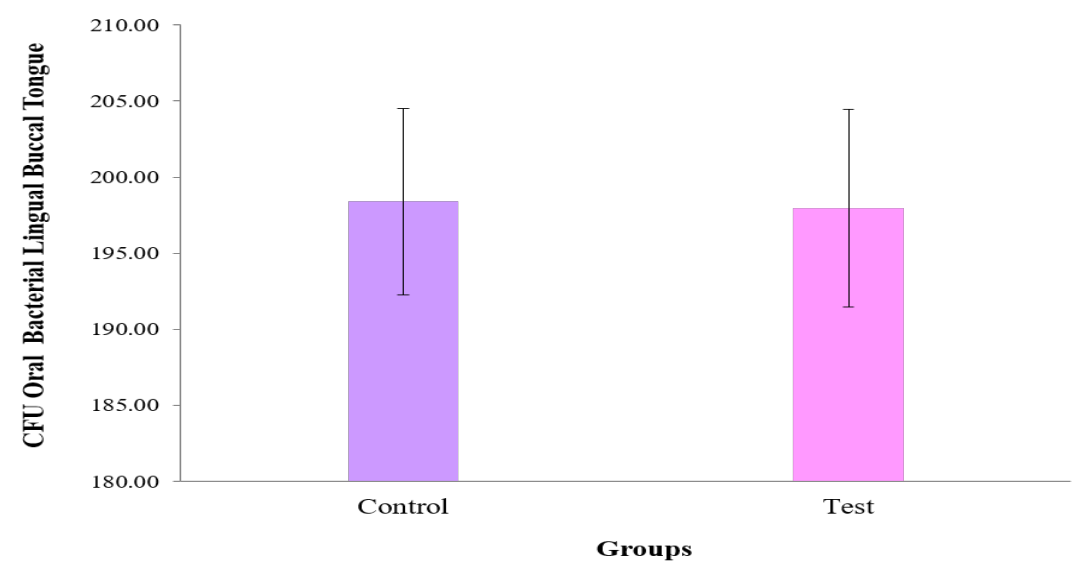

Figure 3. CFU oral bacterial lingual buccal tongue for the control group (without implant) and test group (with implant). 


\section{Discussion}

Bacteria in the oral cavity are often associated with two major oral diseases: caries and periodontal diseases. Diseases appear following an in balance in the oral resident macrobiotic, leading to the emergence of potentially pathogenic bacteria [18].

Several factors may contribute to the increasing or reduction in the number of bacteria colonies inside the oral cavity. The factors include the host, him or herself, oral hygiene care, the existing and complexity of prosthesis in the oral cavity [19]. The recent demanding and popular dental treatment to replace missing teeth implants, for that reason, this study was conducted to compare the number of bacteria colonies in an oral cavity of patients with functioning implants with non-implant patients. There are many researches, which have similar interest with this study however the findings from this study still relevant as this study was conducted among the specific group of subjects with the different way of diet, living style and different expertise of professional with the specific clinical protocol [4]. All the patients in this study have good knowledge and understanding of implant treatment, which is relatively important to pursue the longevity of the implant [20].

The type of implant-abutment connection also plays an essential role in providing a healthy or friendly environment to the alveolar crest around the biological width area where the platform shift's design will prevent the colonization of bacteria at the bony edge closed to connection micro-gap consistent with that mentioned previously [21]. All the implant patients in this study were selected from the patient's record list, Hospital USM, which Dentium implant with platform shift design, was used. The measuring of bacteria colonies used in this study as an indicator to represent the status of the oral cavity with the CFU measurement as conducted by previous studies [22].

The increase in the CFU reading highlighted more colonies of bacteria, whereas the reduction in the CFU reading will represent less bacterial colony as described by other authors [23]. More the colony of bacteria or increase in CFU reading will represent worse oral hygiene as general perception; however, knowing the specific type of bacteria colonies are more significant as compared to a number of colonies present as supported by previous researchers [24].

The difference in oral hygiene status or condition is partly affected by the prosthesis's presence as the superstructure for the implant inside the oral cavity. The rougher surface of the prosthesis will retain more plaque whereas the smoother surface is more favorable for cleaning. The plaque that formed is embedded with bacteria colonies and allows more colonization of bacteria if the accumulation of plaque is failed to cease away by means of oral hygiene care.

In this study, the CFU reading for both implant and non-implant has no significant difference in a number of bacteria colonies. This means that the effect of existing superstructures attached to implant fixtures on bacteria colonies is similar to the presence of teeth in the normal control group. The CFU readings were taken from two sites, which were buccal mucosa and lingual buccal tongue showed no significant difference as compared to non-implant group. These results or findings supported by another article that postulated implant-supported crown are the most accepted treatment in modern dentistry, which are similar to natural teeth in many aspects, such as functions, comfort, and maintenance [25].

The other consideration should be given to the specific colonies of bacteria occupying the oral cavity in these two groups, as the research revealed that the type of bacteria colonies depends on oral hygiene and condition [23]. Although many articles revealed that the type of colonies that are changed; however there are other articles mentioned that both type and amount of colonies are affected and enhance by the increase in plaque accumulation [23,26-28]. In this study, all the subjects have individually fixed prosthesis to implant 
fixtures which warrant almost similar maintenance to normal natural teeth which consistent with which mentioned that oral hygiene maintenance/care highly depends on the complexity of the prosthesis, more complex the prosthesis requires more attention and care [1].

The other study published CFU reading for normal subjects without any implant inside oral cavity more or less similar to this study although they were from different ethnic groups [28]. The possibility of error in counting the colony growths in agar plate could occur, especially if the growths appear to be multilayers; however, in this study, bacterial dilutions, up to five times, were conducted to overcome this problem as suggested previously [24].

The assumption on the number of the bacterial colony with $\mathrm{CFU} / \mathrm{mL}$ using acolyte machine is more useful determination in this study as compared to individual bacteria counting under the microscope because of the possibility of the presence of dead cells, which could result with the false result [29].

The result of this study showed statistically not significant in both areas of a swab taken, however in terms of CFU readings, the CFU reading from buccal mucosa of implant patients is lower than CFU reading from same sites of a normal individual which indicated that surface of a prosthesis supported implant and implant-abutment connection is in favor for the colonization of bacteria plaque as compared to normal tooth surface at cervical region [30]. The difference in CFU reading is more noticeable in a swab taken from buccallingual tongue because the direct effect of saliva, which excreted from wanton's duct opening, acted as a cleansing mechanism to the buccal area is not favored to the lingual buccal tongue area [31].

\section{Conclusion}

There was no significant difference in bacterial load between implant patients and non- implant patients, which suggested that the presence of implants in oral cavity does not interfere or worsen the oral condition nevertheless, the effect of implants on surrounding oral flora is similar to natural teeth. However, the CFU reading of lingual buccal tongue was higher in non-implant patients than in implant patients, indicating that the implants are less susceptible to the plaque attachment. In contrast, CFU reading for buccal mucosa for both groups is similar because of the direct cleansing mechanism by saliva excreted from the parotid gland.

\section{Authors' Contributions}

\begin{tabular}{|c|c|c|}
\hline JBAM & (D) $0000-0002-8804-8329$ & $\begin{array}{l}\text { Conceptualization, Methodology, Investigation, Formal Analysis, Writing - } \\
\text { Original Draft Preparation and Writing - Review and Editing. }\end{array}$ \\
\hline SAR & (D) $0000-0001-9216-4026$ & $\begin{array}{l}\text { Conceptualization, Methodology, Investigation, Formal Analysis, Writing - } \\
\text { Original Draft Preparation and Writing - Review and Editing. }\end{array}$ \\
\hline $\mathrm{SH}$ & (D) $0000-0002-7445-1416$ & $\begin{array}{l}\text { Conceptualization, Writing - Original Draft Preparation and Writing - Review } \\
\text { and Editing. }\end{array}$ \\
\hline MKA & (D) $0000-0001-7131-1752$ & $\begin{array}{l}\text { Conceptualization, Writing - Original Draft Preparation and Writing - Review } \\
\text { and Editing. }\end{array}$ \\
\hline
\end{tabular}

\section{Financial Support}

None.

\section{Conflict of Interest}

The authors declare no conflicts of interest. 


\section{References}

[1] Pye AD, Lockhart DEA, Dawson MP, Murray CA, Smith AJ. A review of dental implants and infection. J Hosp Infec 2009; 72(2): 104-10. https://doi.org/10.1016/j.jhin.2009.02.010

[2] Nascimento C, Miani PK, Pedrazzi V, Gonçalves RB, Ribeiro RF, Faria ACL, et al. Leakage of saliva through the implant-abutment interface: in vitro evaluation of three different implant connections under unloaded and loaded conditions. Int J Oral Maxillofac Implants 2012; 27(3):551-60.

[3] Ujiie Y, Todescan R, Davies JE. Peri-implant crestal bone loss: a putative mechanism. Int J Dent 2012; $2012: 742439$. https://doi.org/10.1155/2012/742439

[4] Quirynen M, De Soete M, van Steenberghe D. Infectious risks for oral implants: A review of the literature. Clin Oral Implants Res 2002; 13(1):1-19. https://doi.org/10.1034/j.1600-0501.2002.130101.x

[5] Heydenrijk K, Meijer HJ, van der Reijden WA, Raghoebar GM, Vissink A, Stegenga B. Microbiota around root-form endosseous implants: a review of the literature. Int J Oral Maxillofac Implants 2002; 17(6):829-38.

[6] Tanner A, Maiden MF, Lee K, Shulman LB, Weber HP. Dental implant infections. Clin Infect Dis 1997; 25(Suppl 2):S2 13-7. https://doi.org/10.1086/516243

[7] Carinci F, Gaudio RM. Peri-implantitis and periodontitis: Use of bacteriological test in dental practice. Forens Med Anatom Res 2013; 1(3):50-6. https://doi.org/10.4236/fmar.2013.13010

[8] Violant D, Galofré M, Nart J, Teles RP. In vitro evaluation of a multi species oral biofilm on different implant surfaces. Biomed Mater 2014; 9(3):035007. https://doi.org/10.1088/1748-6041/9/3/035007

[9] Mongra AC. Dental implant infections and decontamination. Int J Biomed Adv Res 2012; 3(10):736-46. https://doi.org/10.7439/ijbar.v3i10.760

[10] Shahabouee M, Rismanchian M, Yaghini J, Babashahi A, Badrian H, Goroohi H. Microflora around teeth and dental implants. Dent Res J (Isfahan) 2012; 9(2):2 15-20. https://doi.org/10.4103/1735-3327.95239

[11] Dhir S. Biofilm and dental implant: the microbial link. J Indian Soc Periodontol 2013; 17(1):5-11. https://doi.org/10.4103/0972-124X.107466

[12] Elsayed ME, Sultan KO, Abd EL hameed HM, Elsayed AE. Detection of bacterial colonization around cobalt chromium versus zirconium copings on natural teeth supporting over denture. Two different in vitro studies. J Am Sci 2012; 8(7):799-803.

[13] Grover HS, Shukla S. Microbiology of dental implant: a review of literature. Int J Oral Implant Clin 2012; 3(1):43-6. https://doi.org/10.5005/JP-Journals-10012-1064

[14] Dorkhan M, Yücel-Lindberg T, Hall J, Svensäter G, Davies JR. Adherence of human oral keratinocytes and gingival fibroblasts to nano-structured titanium surfaces. BMC Oral Health 2014; 14:75. https://doi.org/10.1186/1472-6831-14-75

[15] Rouabhia M. Interactions between host and oral commensal microorganisms are key events in health and disease status. Can J Infect Dis 2002; 13(1):47-51. https://doi.org/10.1155/2002/580476

[16] Abu-Ta'a M, Quirynen M, Teughels W, van Steenberghe D. Asepsis during periodontal surgery involving oral implants and usefulness of peri-operative antibiotics: a prospective, randomized, controlled clinical trial. J Clin Periodontol 2008; 35(1):58-63. https://doi.org/10.1111/j.1600-051X.2007.01162.x

[17] Al-Brazenji HA, Al-Jubouri R, Taher Z. The effect of static magnetic field on some oral microorganisms (an in vitro study). Tikrit Med J 2010; 16(2):34-8.

[18] Marcotte H, Lavoie MC. Oral microbial ecology and the role of salivary immunoglobulin A. Microbiol Mol Biol Rev 1998; 62(1):71-109

[19] Bello OO, Osho A, Bankole SA, Bello TK. Antibiotic susceptibility profiles and bacteriological risks associated with used toothbrushes: a case study of some apparently healthy university students in Southwestern Nigeria. Am Int J Biol 2013; 1(1):1-12.

[20] Yao J, Tang H, Gao XL, McGrath C, Mattheos N. Patients' expectations to dental implant: a systematic review of the literature. Health Qual Life Outcomes 2014; 12:153. https://doi.org/10.1186/s12955-014-0153-9

[21] Al-Juboori MJ, Ab Rahman S. Causes of Crestal Bone Resorption in the Dental Implant patient. Dent Implantol Update 2012; 23(7):49-56.

[22] Grez PAV, Godoy EF, Fluxá PP, Cortés GAM, Saad JRC, Casielles JM. Is there a difference of streptococcus mutans count and adherence on amalgam and resin occlusal restorations? a blind clinical study. Braz J Oral Sci 2015; 14(1):59. https://doi.org/10.1590/1677-3225v14n 1a02

[23] Bordas A, McNab R, Staples AM, Bowman J, Kanapka J, Bosma MP. Impact of different tongue cleaning methods on bacterial load of the tongue dorsum. Arch Oral Biol 2008; 53(Suppl 1):S13-8. https://doi.org/10.1016/So003-9969(08)70004-9

[24] Listgarten MA, Lai CH. Comparative microbiological characteristics of failing implant and periodontally diseased teeth. J Periodontol 1999; 70(4):431-7. https://doi.org/10.1902/jop.1999.70.4.431

[25] Meijer HJA, Stellingsma K, Meijndert L, Raghoebar GM. A new index for rating aesthetic of implant-supported single crowns and adjacent soft tissue-the implant crown aesthetic index. A pilot study on the validation of a new index. Clin Oral Implants Res 2005; 16(6):645-9. https://doi.org/10.1111/j.1600-0501.2005.01128.x 
[26] Ahrné S, Nobaek S, Jeppsson B, Adlerberth I, Wold AE, Molin G. The normal lactobacillus flora of healty human rectal and oral mucosa. J Appl Microbiol 1998; 85(1):88-94. https://doi.org/10.1046/j.1365-2672.1998.00480.x

[27] Listgarten MA, Lai CH. Comparative microbiological characteristics of failing implant and periodontally diseased teeth. J Periodontol 1999; 7O(4):431-7. https://doi.org/10.1902/jop.1999.70.4.431

[28] Casemiro LA, Martins CHG, Carvalho TC, Panzeri H, Lavrador MAS, Pires-de-Souza FCP. Effective of new toothbrush design versus a conventional tongue scraper in improving breath odor and reducing tongue microbiota. J Appl Oral Sci 2008; 16(4):271-4. https://doi.org/10.1590/s1678-77572008000400008

[29] Al-Aaskari SK, Ariffin Z, Hussein A, Reza F. Comparison of microbial adherence to polymethylmethacrylate for maxillo-facial prostheses. World Appl Sci J 2014; 31(12):2 115-9. https://doi.org/10.5829/idosi.wasj.2014.31.12.8432

[30] Gurenlian JR. The role of dental plague biofilm in oral health. J Dent Hygin 2007; 81:5.

[31] Culp DJ, Robinson B, Parkkila S, Pan PW, Cash MN, Truong HN, et al. Oral colonization by streptococcus mutans and caries development is reduced upon deletion of carbonic anhydrase VI expressions in saliva. Biochim Biophys Acta 2011;1812(12):1567-76. https://doi.org/10.1016/j.bbadis.2011.09.006 